\title{
Solution behaviour of lead(II) carboxylates in organic solvents
}

\author{
Hugh D. Burrows ${ }^{\mathrm{a}, *}$, Maria da Graça Miguel ${ }^{\mathrm{a}}$, Rui P.C. Pereira ${ }^{\mathrm{a}}$, Nuno M.B. Proença ${ }^{\mathrm{a}}$, \\ Sónia M.C. Cardoso ${ }^{\mathrm{a}}$, Carlos F.G.C. Geraldes ${ }^{\mathrm{b}}$, M. Helena Gil ${ }^{\mathrm{c}}$, Wyn Brown ${ }^{\mathrm{d}}$ \\ a Departamento de Química, Universidade de Coimbra, 3004-535 Coimbra, Portugal \\ ${ }^{\mathrm{b}}$ Departamento de Bioquímica, Universidade de Coimbra, 3004-535 Coimbra, Portugal \\ ${ }^{\mathrm{c}}$ Departamento de Engenharia Química, Universidade de Coimbra, 3004-535 Coimbra, Portugal \\ ${ }^{\mathrm{d}}$ Department of Physical Chemistry, University of Uppsala, Box 532, S-75121 Uppsala, Sweden
}

Received 29 February 2004; accepted 15 June 2004

Available online 18 September 2004

\begin{abstract}
The solution behaviour has been studied of a series of even chain length lead(II) carboxylates (octanoate to octadecanoate) and the odd chain length lead(II) heptadecanoate in a variety of non-complexing organic solvents and in alcohols. In agreement with previous studies, solubility increases dramatically above a certain temperature, which depends on solute concentration, chain length and solvent. This solution temperature is also affected by traces of water. These results are complemented by studies using vapour pressure osmometry, dynamic light scattering, ${ }^{1} \mathrm{H}$ and ${ }^{13} \mathrm{NMR}$ spectroscopy. The results in water-free systems are consistent with the formation of rather ill-defined, polydisperse aggregates, which increase in size with concentration and decrease with temperature. These show similar local structure to lamellar mesophases in the pure lead(II) carboxylates, and are suggested to be formed by solvent induced swelling and break-up of these mesophases. In the presence of water, a more ordered structure is formed, in which a few water molecules are suggested to be bound to the lead(II) carboxylate headgroup. (C) 2004 Elsevier B.V. All rights reserved.
\end{abstract}

Keywords: Solution behaviour; Lead(II) carboxylates; Organic solvents

\section{Introduction}

The factors responsible for the formation of aggregates by amphiphilic molecules in aqueous solutions are well established [1-4], and there is a vast literature of experimental data which supports theoretical predictions. However, much less is understood about aggregation of these molecules in water-free organic solvents. The long chain carboxylates of divalent metal ions (metal soaps) are an important group of compounds, which find applications as emulsifiers, paint driers, grease thickeners, dispersant agents, etc. [5-8]. They are also used in solvent extraction procedures [9], and may find interesting materials applications in metal-organic mesogen systems $[10,11]$. They are, in general, insoluble in water, but dissolve in a variety of organic solvents. Although these sys-

* Corresponding author. Tel.: +351 239 854482; fax: +351 239827703. E-mail address: burrows@ci.uc.pt (H.D. Burrows). tems have been extensively studied for over 90 years [12-43], and a number of reviews have been presented [44-48], there is still a shortage of information on the nature of the aggregates present, which limits the development of good models of the solution behaviour. Some general features can, however, be described. Firstly, the solubilities of the saturated metal carboxylates at room temperature are generally low, but increase dramatically above a certain temperature $[13,16,31,44]$. This critical temperature shares many of the characteristics of the Krafft point observed with aqueous surfactants [26,31], but probably has a different origin. We will refer to it as the solubility temperature $\left(t_{\mathrm{sol}}\right)$. Secondly, introduction of unsaturation or chain branching into the chain decreases the solubility temperature [48], and soaps, such as oleates [23,32], are frequently soluble at room temperature. Thirdly, in nonpolar or noncoordinating solvents, evidence has been presented from ebullioscopic measurements $[16,18]$, viscosimetry [23,32], UV-vis absorption spectra [30,40] and fluorescence depo- 
larisation [20] for the existence of aggregates in solution. However, in contrast to the behaviour of amphiphiles in aqueous solutions $[3,4]$ these appear to be ill-defined, and enormous variations are observed in the aggregation numbers obtained by the various techniques. In contrast, in coordinating solvents, such as pyridine, the carboxylates exist as the monomers [19], probably due to complexing by the solvent.

The solubility behaviour depends on the metal ion, chain length of the carboxylate, the presence of any substituents, and the solvent $[31,44,47,48]$. These properties may also be dramatically affected by the presence of any water $[22,32,44]$, and in some cases, gelation may occur $[32,44]$. With the branched chain copper(II) 2-ethylhexanoate, gel formation has been observed even in the absence of water $[35,36]$.

While molecular dynamics simulations [49] support the idea of amphiphile aggregation in non-polar, water-free media, thermodynamic considerations [50] suggest that these are not well defined micelles, as observed in aqueous solutions, but are polydisperse, with predominantly small aggregates, but the presence of some larger ones. Because of the rather ill-defined nature of these aggregates, there is need for more detailed experimental data.

In this study, we will discuss the particular case of the solubility behaviour of some lead(II) carboxylates. These are available in a high state of purity, and their thermal behaviour has been extensively studied [51-56]. Some aspects of the solubility behaviour of these compounds have been previously addressed [31]. We will concentrate initially on general aspects of the solubility behaviour in a variety of solvents, including the effect of added water. Subsequently, we will apply a variety of techniques to attempt to find more information on the aggregates present.

\section{Experimental}

The solubility behaviour has been studied of the even chain length lead(II) carboxylates from the octanoate to the octadecanoate, and the odd chain lead(II) heptadecanoate. For convenience, these will be abbreviated $\mathrm{PbC}_{n}$, where $n$ is the total carbon chain length. The synthesis and characterization of these compounds has previously been reported [55], and purity was confirmed by differential scanning calorimetry, and good elemental analyses obtained for $\mathrm{C}, \mathrm{H}$ and $\mathrm{Pb}$. In addition, the absence of water or excess acid (the most common impurities) was shown from their infrared spectra. Solvents were of the purest grade available, and were used as supplied. The general technique used for solubility temperature measurements has previously been described in detail [31]. The error of duplicate measurements is not more than $2 \%$, and the solubility temperatures are reproducible to $\pm 0.5^{\circ} \mathrm{C}$. Vapour pressure osmometry measurements were made on a Hewlett-Packard 302 apparatus at $70^{\circ} \mathrm{C}$. This was calibrated using solutions of various known concentrations of benzil $(0.025-0.1 \mathrm{M})$ in toluene. Details of the apparatus and techniques for dynamic light scattering measurements have been described in detail elsewhere [57]. Measurements used $488 \mathrm{~nm}$ light from a frequency stabilized $\mathrm{Ar}$ ion laser. Samples were contained in scattering cells in a thermostat bath containing an index-matching liquid. The autocorrelation curves obtained were analysed by an inverse Laplace transformation to obtain the distribution of relaxation times using the algorithm REPES [58,59], as incorporated in the analysis package GENDIST. Details of data analysis have previously been given [58]. NMR spectral studies used a Varian XL-200 spectrometer operating at $200.06 \mathrm{MHz}\left({ }^{1} \mathrm{H}\right)$ or $50.31 \mathrm{MHz}\left({ }^{13} \mathrm{C}\right)$, as described elsewhere [60]. In all cases, TMS was used as reference.

\section{Results}

\subsection{Solubility temperature measurements}

As previously noted [31] at room temperature, all the even chain length lead(II) carboxylates of saturated carboxylic acids studied showed very low solubility in the solvents studied, but showed dramatic increases above a certain critical temperature $\left(t_{\text {sol }}\right)$. Values of $t_{\text {sol }}$ were determined by visual observation for solutions of the octanoate and decanoate $\left(\mathrm{PbC}_{8}\right.$ and $\left.\mathrm{PbC}_{10}\right)$ in a variety of solvents as a function of concentration (Table 1). For the two solvents, octanol and toluene, solution temperatures were also measured as a function of chain length for all the lead(II) carboxylates (Table 2). In all cases, a slight increase in $t_{\text {sol }}$ with concentration was observed above the critical solubility temperature, in agreement with previous observations in related systems [16-19,31,34]. For convenience, phase transition temperatures for the pure soaps are also included in Table 2. From ebullioscopic measurements [16-19], it is suggested that this is accompanied by the growth of carboxylate aggregates. In addition, as previously observed for long chain carboxylates of various divalent

Table 1

Solution temperatures $\left(t_{\text {sol }},{ }^{\circ} \mathrm{C}\right)$ of lead(II) octanoate $\left(\mathrm{PbC}_{8}\right)$ and decanoate $\left(\mathrm{PbC}_{10}\right)$ in various solvents as function of solute concentration

\begin{tabular}{lrrrr}
\hline & \multicolumn{4}{l}{ Concentration (wt.\%) } \\
\cline { 2 - 5 } & 5 & 10 & 15 & 20 \\
\hline $\mathrm{PbC}_{8}$ & 64 & 68 & 73 & 78 \\
Toluene & 67 & 71 & 76 & 81 \\
Xylene & 72 & 75 & 79 & 83 \\
Ethyleneglycol monomethyl ether & 92 & 98 & 104 & 109 \\
Glycerol & 61 & 66 & 70 & 74 \\
Pentanol & 69 & 74 & 77 & 82 \\
Octanol & & & & \\
PbC 10 & 67 & 72 & 76 & 84 \\
Toluene & 70 & 74 & 78 & 86 \\
Xylene & & & & \\
Ethyleneglycol & 76 & 80 & 84 & 89 \\
Monomethyl ether & 95 & 101 & 106 & 113 \\
Glycerol & 67 & 71 & 74 & 78 \\
Pentanol & 73 & 78 & 81 & 87 \\
Octanol & & & & \\
\hline
\end{tabular}


Table 2

Solution temperatures $\left(t_{\mathrm{sol}},{ }^{\circ} \mathrm{C}\right)$ of lead(II) carboxylates in toluene and octanol as functions of carboxylate chain length together with phase transition temperatures for pure soaps

\begin{tabular}{|c|c|c|c|c|}
\hline \multirow{2}{*}{$\begin{array}{l}\text { Carbon chain } \\
\text { length }\end{array}$} & \multicolumn{4}{|c|}{ Concentration (wt.\%) } \\
\hline & 5 & 10 & 15 & 20 \\
\hline \multicolumn{5}{|l|}{ Toluene } \\
\hline 8 & 64 & 68 & 73 & 78 \\
\hline 10 & 67 & 72 & 76 & 84 \\
\hline 12 & 72 & 77 & 81 & 86 \\
\hline 14 & 78 & 83 & 89 & 93 \\
\hline 16 & 81 & 87 & 92 & 98 \\
\hline 17 & 86 & 92 & 97 & 104 \\
\hline 18 & 92 & 98 & 104 & 109 \\
\hline \multicolumn{5}{|l|}{ Octanol } \\
\hline 8 & 69 & 74 & 77 & 82 \\
\hline 10 & 73 & 78 & 81 & 87 \\
\hline 12 & 77 & 83 & 87 & 91 \\
\hline 14 & 81 & 85 & 89 & 94 \\
\hline 16 & 86 & 90 & 94 & 99 \\
\hline 17 & 91 & 95 & 102 & 106 \\
\hline \multirow[t]{2}{*}{18} & 94 & 101 & 107 & 113 \\
\hline & $\begin{array}{l}\text { Solid } \rightarrow \\
\text { mesophase I }\end{array}$ & $\begin{array}{l}\text { Mesophase I } \rightarrow \\
\text { mesophase II/liquid }\end{array}$ & $\begin{array}{l}\text { Mesophase II } \rightarrow \\
\text { liquid }\end{array}$ & \\
\hline \multicolumn{5}{|c|}{ Phase transitions in pure soaps ${ }^{\mathrm{a}}$} \\
\hline 8 & 80 & 82 & 109 & \\
\hline 10 & 84 & 96 & 112 & \\
\hline 12 & 94 & 105 & 107 & \\
\hline 14 & 102 & 110 & & \\
\hline 16 & 104 & 112 & & \\
\hline 17 & 106 & 114 & & \\
\hline 18 & 108 & 115 & & \\
\hline
\end{tabular}

${ }^{a}$ Average values from data in [8].

metals [31], for the same solvent, $t_{\text {sol }}$ increases with the carboxylate chain length. Both solute-solute and solute-solvent interactions are expected to be involved in this case [31]. Also, in agreement with results on related systems [31,34], $t_{\text {sol }}$ depends markedly on the solvent. This will be considered in more detail in Section 4, but we note particularly high $t_{\text {sol }}$ values are observed in glycerol, possibly due to its strongly hydrogen bonded structure.

\subsection{Effect of added water}

The effect of adding water on the solubility temperatures was observed for $5 \%$ solutions in various solvents. Typical data are shown in Fig. 1, and show an initial decrease in temperature, which then reaches a constant value. At the highest water concentrations, solutions become slightly cloudy, suggesting phase separation, although it was difficult to determine accurately the maximum water solubility. However, it is clear that the water concentration in these solutions is considerably higher than in the pure solvents. For comparison, the solubility of water in pure toluene and xylene at $25^{\circ} \mathrm{C}$ are $0.21 \%$ and $0.038 \%$, respectively [61]. Further, although, as suggested by a referee, addition of water can lead to hydrolysis of long chain carboxylates and produce ba-

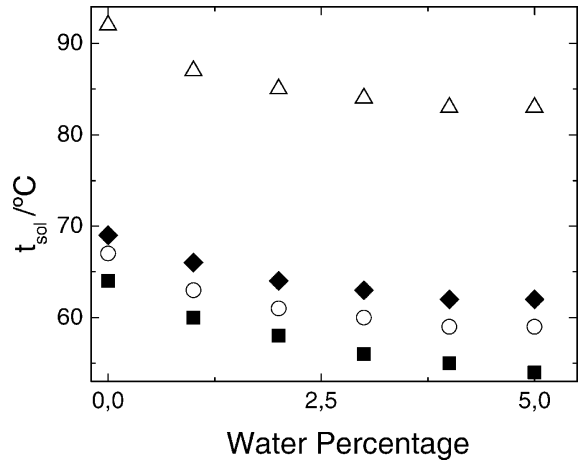

Fig. 1. Plots of solution temperature against percentage of water for solutions of lead(II) decanoate (5 wt.\% solutions) in toluene $(\mathbf{\square})$, xylene $(\bigcirc)$, glycerol $(\triangle)$ and octanol $(\diamond)$.

sic soaps [8], no evidence for this was found in the present study.

\subsection{Vapour pressure osmometry}

Solutions of $\mathrm{PbC}_{8}(0.025-0.1 \mathrm{M})$ in toluene were studied by vapour pressure osmometry at $70^{\circ} \mathrm{C}$. A graph of $\Delta R / C$ against concentration $(C)$ was linear (Fig. 2), and by extrapolation to zero concentration and use of calibration coefficient determined with benzil in the same solvent, a molecular weight of 773 was determined. Care is needed in interpretation of data from vapour pressure osmometry in this type of system [18], particularly as the aggregation is concentration dependent. However, the value is significantly higher than the molecular weight of monomeric $\mathrm{PbC}_{8}$ (493), supporting the existence of some aggregation in solution. The experiment was repeated in the same concentration range in the presence of water $(5 \%(\mathrm{v} / \mathrm{v}))$, and from the intercept of the graph (Fig. 2) a molecular weight of 1467 was calculated. Results are summarised in Table 3, and do indicate differences in aggregation behaviour between $\mathrm{PbC}_{8}$ in pure toluene and in toluene in the presence of water.

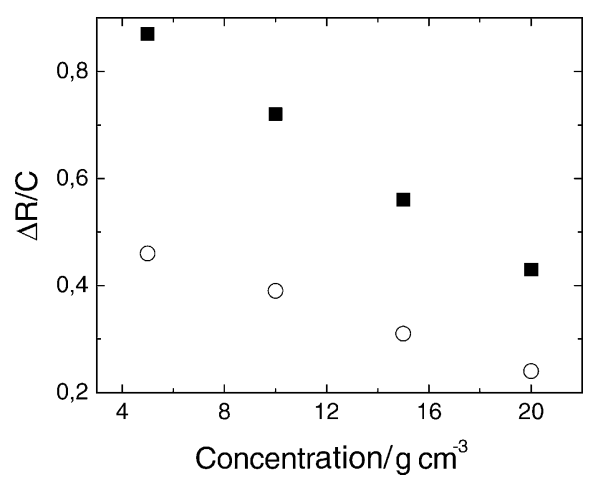

Fig. 2. Vapour pressure osmometry data for various concentrations of lead(II) octanoate in solution in toluene: $(\mathbf{\square})$ alone; $(\bigcirc)$ with $5 \%$ water. 
Table 3

Vapour pressure osmometry results on solutions of lead(II) decanoate in toluene

\begin{tabular}{lc}
\hline & $\begin{array}{l}\text { Calculated molecular } \\
\text { weight }\end{array}$ \\
\hline Theoretical values for $\mathrm{PbC}_{10}$ & 493 \\
Value for solution $(0.025-0.1 \mathrm{M})$ in toluene at & 773 \\
$\quad 70^{\circ} \mathrm{C}$ & \\
Value for solution $(0.025-0.1 \mathrm{M})$ in toluene & 1467 \\
$\quad$ with $5 \%(\mathrm{v} / \mathrm{v})$ water & \\
\hline
\end{tabular}

\subsection{Dynamic light scattering measurements}

Further indications of differences in aggregation in the presence and absence of water came from dynamic light scattering (DLS). DLS measurements were made on solutions of $\mathrm{PbC}_{10}$ in toluene at various concentrations and temperatures. Decay time distributions for various concentrations at $75^{\circ} \mathrm{C}$ are shown in Fig. 3a. The presence of peaks at long relaxation times clearly shows that the samples are polydisperse. However, the most intense peak has the shortest relaxation time $\left(\Gamma_{\text {fast }}\right)$, and is sharp and fairly well defined. Although the difficulties of separating effects of aggregate growth from inter-aggregate interactions in light scattering data from such systems have been highlighted [62], qualitative information on aggregate size was obtained for this peak. If we assume that the relaxation time corresponds to a diffusion process, diffusion coefficients can be calculated from the relationship

$D_{\text {fast }}=\frac{\Gamma_{\text {fast }}}{q^{2}}$

The scattering vector, $q$, is given by

$q=4 \pi n_{\mathrm{o}} \sin (\theta / 2) / \lambda_{\mathrm{o}}$

where $n_{\mathrm{o}}$ is the solvent refractive index, $\theta$ is the scattering angle $\left(90^{\circ}\right)$ and $\lambda_{\mathrm{o}}$ is the laser wavelength. Diffusion coefficients were calculated, and from these indications of aggregate size obtained. Although the aggregates are unlikely to be spherical, we can estimate a limiting hydrodynamic radius $\left(R_{\mathrm{h}}\right)$
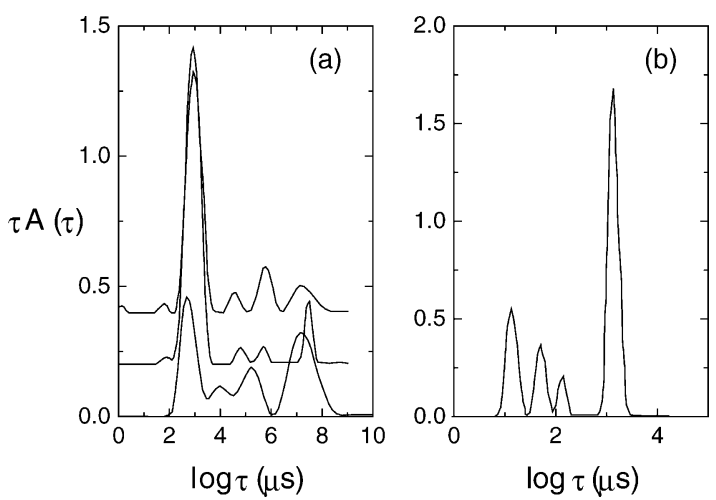

Fig. 3. Decay time distributions for solutions of lead(II) decanoate in toluene at $75^{\circ} \mathrm{C}$ : (a) as a function of solute concentration: bottom to top: 5,10 and 15 wt. $\%$ solutions; (b) $15 \mathrm{wt} . \%$ solution in the presence of water at $75^{\circ} \mathrm{C}$.
Table 4

Hydrodynamic radii determined from dynamic light scattering for solutions of lead(II) decanoate in toluene at various temperatures

\begin{tabular}{ccl}
\hline Temperature $\left({ }^{\circ} \mathrm{C}\right)$ & Concentration $(w t . \%)$ & $R_{\mathrm{H}}(\mathrm{nm})^{\mathrm{a}}$ \\
\hline 75.0 & 5.07 & 257 \\
75.0 & 9.92 & 391 \\
75.0 & 13.11 & 448 \\
90.0 & 13.11 & 316 \\
100.0 & 13.11 & 213 \\
75.0 & 13.11 (with water) & 132 \\
\hline
\end{tabular}

${ }^{a}$ Calculated from diffusion coefficient for the fastest peak in the decay time distribution.

assuming a spherical structure by using the Stokes-Einstein relationship [58]

$R_{\mathrm{h}}=\frac{k T}{6 \pi \eta D_{\mathrm{o}}}$

where $\eta$ is the solvent viscosity, taken as $0.354 \mathrm{cP}$ for toluene at $75^{\circ} \mathrm{C}$ [63]. Results are presented in Table 4, and from extrapolation to zero concentration, a limiting effective hydrodynamic radius of $184 \mathrm{~nm}$ was calculated for these aggregates. This can be compared with results on cobalt hydroxy monooleate in heptane solutions, where a $z$-averaged radius of gyration of $320 \mathrm{~nm}$ was determined for dilute solutions [32].

Using the same relationships, apparent hydrodynamic radii were calculated for the fast component at various temperatures (Table 4). Although the polydispersity and asymmetry of these aggregates means the values only have qualitative significance, the results clearly suggest that aggregates grow with concentration, in agreement with results of ebullioscopic measurements [16-19] and theoretical predictions [50], and that they get smaller on increasing temperature.

The effect of adding water on the scattering was observed at $75^{\circ} \mathrm{C}$ (Fig. 3b). Although detailed analysis of the complex behaviour observed is beyond the scope of this work, in agreement with the vapour pressure osmometry results it is clear that quite dramatic differences are seen between the system in the absence and presence of water.

\subsection{Multinuclear NMR spectral studies}

The ${ }^{1} \mathrm{H}$ NMR spectrum was run of a solution of $\mathrm{PbC}_{10}$ in toluene $\left(\mathrm{d}^{8}\right)$ at 80,90 and $100{ }^{\circ} \mathrm{C}$ (Table 5). Peaks were observed in the same region as those observed in molten lead(II) decanoate at $110^{\circ} \mathrm{C}$ [64], and very small changes in chemical

Table 5

${ }^{1} \mathrm{H}$ NMR spectral data for lead(II) decanoate as neat compound and $20 \%$ solution in perdeuterotoluene

\begin{tabular}{lllll}
\hline Assignment & \multicolumn{4}{l}{ Chemical shift (ppm relative to TMS) } \\
\cline { 2 - 5 } & $80{ }^{\circ} \mathrm{C}$ & $90{ }^{\circ} \mathrm{C}$ & $100{ }^{\circ} \mathrm{C}$ & $80{ }^{\circ} \mathrm{C}$ with $\mathrm{D}_{2} \mathrm{O}$ \\
\hline $\mathrm{CH}_{3}$ & 0.950 & 0.928 & 0.898 & 0.929 \\
$\mathrm{CH}_{2}(n)$ & 1.372 & 1.443 & 1.507 & 1.339 \\
$\mathrm{CH}_{2}(3)$ & 1.840 & 1.842 & 1.882 & 1.740 \\
$\mathrm{CH}_{2}(2)$ & 2.473 & 2.498 & 2.515 & 2.158 \\
\hline
\end{tabular}




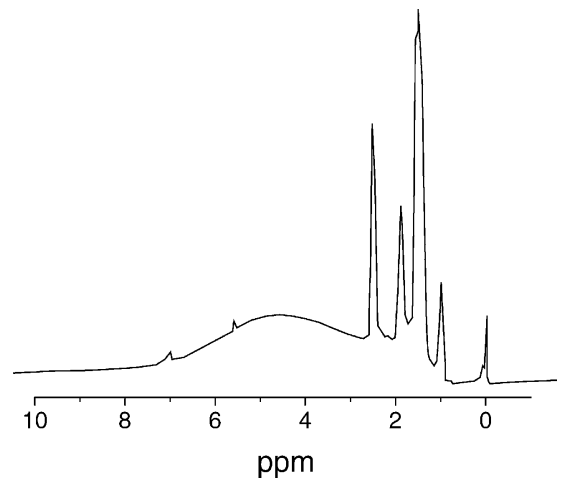

Fig. 4. ${ }^{1} \mathrm{H}$ NMR spectrum of lead(II) decanoate in perdeuterotoluene at $80^{\circ} \mathrm{C}$ in the presence of $\mathrm{D}_{2} \mathrm{O}$.

shift were observed on increasing temperature. On addition of a small quantity of $\mathrm{D}_{2} \mathrm{O}$, only minor changes were observed in the positions of these peaks, although these were most marked for $\mathrm{CH}_{2}(2)$ and $\mathrm{CH}_{2}$ (3) groups, and in addition, an additional broad peak, due to trace water and HOD, was observed around $4.3 \mathrm{ppm}$ (Fig. 4, Table 5).

$$
\left(\mathrm{CH}_{3} \mathrm{CH}_{2}(9) \mathrm{CH}_{2}(8) \mathrm{CH}_{2}(4-7) \mathrm{CH}_{2}(3) \mathrm{CH}_{2}(2) \mathrm{CO}_{2}\right)_{2} \mathrm{~Pb}
$$

Further information on the carboxylate structure in solution came from ${ }^{13} \mathrm{C}$ NMR spectra. Spectral data measured for $\mathrm{PbC}_{10}$ in toluene at $80^{\circ} \mathrm{C}$ are presented in Table 6, together with assignment of the peaks, and ${ }^{13} \mathrm{C}$ spectra previously reported for this compound in the solid, lamellar $\mathrm{L}_{\alpha}$ and molten liquid phases [60]. The chemical shifts of all the peaks, except the carboxylate and adjacent methylene group, are shifted relative to those of the solid soap. Such changes are usually attributed to the introduction of conformational disordering in the alkyl chain [65]. The chemical shifts in solutions are intermediate between those in the solid and liquid phase, and are closest to those for the mesophase. Direct comparison is difficult, because the spectra were recorded at different temperatures and conformational disordering is

Table 6

${ }^{13} \mathrm{C}$ NMR spectral data for lead(II) decanoate as neat compound and $20 \%$ solution in perdeuterotoluene

\begin{tabular}{lccccc}
\hline Assignment & \multicolumn{5}{l}{ Chemical shift (ppm relative to TMS $)$} \\
\cline { 2 - 6 } & $\begin{array}{l}\text { Solid } \\
\left(60^{\circ} \mathrm{C}\right)^{\mathrm{a}}\end{array}$ & $\begin{array}{l}\mathrm{L}_{\alpha} \\
\text { phase }^{\mathrm{a}}\end{array}$ & $\begin{array}{l}\text { Liquid } \\
\left(125^{\circ} \mathrm{C}\right)^{\mathrm{a}}\end{array}$ & \multicolumn{2}{l}{ Solution $\left(20 \%\right.$ in $\left.\mathrm{C}_{7} \mathrm{D}_{8}\right)$} \\
\cline { 5 - 6 } & 183.8 & 182.7 & 183.5 & 184.4 & 84.4 \\
\hline $\mathrm{CO}_{2}$ & 40.8 & 40.5 & 40.1 & 40.4 & 39.5 \\
$\mathrm{CH}_{2}(2)$ & 38.9 & & & & \\
& 27.7 & 25.7 & 25.3 & 26.2 & 26.2 \\
$\mathrm{CH}_{2}(3)$ & 27.1 & & & & \\
$\mathrm{CH}_{2}(4-7)$ & 32.7 & 30.2 & 29.4 & 30.5 & 30.1 \\
& 31.3 & & & & \\
$\mathrm{CH}_{2}(8)$ & 34.2 & 31.9 & 31.5 & 32.5 & 32.5 \\
$\mathrm{CH}_{2}(9)$ & 24.9 & 22.0 & 22.0 & 23.1 & 23.1 \\
$\mathrm{CH}_{3}$ & 14.8 & 14.0 & 13.2 & 14.3 & 14.3 \\
\hline
\end{tabular}

${ }^{\mathrm{a}}$ From [54]. temperature dependent. In addition, with toluene solutions there may be a contribution from the "ring current" of the solvent. However, this is unlikely to affect the relative chemical shift changes, and the results are consistent with aggregates being formed, with conformationally disordered chains, and with local structures similar to those in the lamellar mesophase.

Spectra were also run on solutions in the presence of water, and data is included in Table 6. The positions of the majority of peaks were unchanged. However, a shift was seen in the position of the $\mathrm{CH}_{2}(2)$ band. As with the other peaks, this signal is dependent on conformation, and in the solid state is split into two [60], with one component at higher field and one at lower field than the solution in the presence of water. The solution results suggest changes in the structure due to head group hydration on incorporation of water.

\section{Discussion}

Although a number of experimental studies have confirmed the existence of aggregates when amphiphiles are dissolved in water-free organic solvents [16-48], Ruckenstein and Nagarajan have suggested from detailed thermodynamic considerations [50] that these are likely to be mainly dimers and trimers, with a small fraction of larger aggregates. The present results confirm the presence of polydisperse, ill-defined aggregates. Molecular weight averages for polydisperse systems depend upon the technique used, with colligative properties, such as vapour pressure osmometry, giving number average values, and scattering methods giving weight average values [66]. Although, as discussed in Section 3 , caution needs to be exercised in analysis of vapour pressure osmometry data when aggregate size is concentration dependent, and the actual values determined in the present study on lead(II) carboxylates in toluene solution probably underestimate aggregate size, they are consistent with there being mainly small, and rather ill-defined aggregates present. In contrast, light scattering results predominantly from the largest species present in solution [66], and although the absolute values of aggregate sizes determined in the present study must be treated with caution due to the difficulties of treating polydisperse systems, the dynamic light scattering data do confirm the existence of some percentage of larger aggregates in these systems. Further, these grow on increasing concentration. Although from the present data it is difficult to estimate the percentage of the larger aggregates, the results are consistent with the majority of surfactant molecules being present as small aggregates.

From consideration of results on the phase behaviour of lead(II) carboxylate/alkane systems [67], together with the present NMR data, it is possible to propose a model for dissolution of the amphiphile in water-free organic solvents. Although differences are observed in structural assignments, all reports show that upon heating pure long chain lead(II) car- 
boxylates, one or more lamellar mesophases are observed between the solid and isotropic liquid [51-56]. Transition temperatures for these are given in Table 2. On adding undecane (hendecane) to lead(II) dodecanoate, the lamellar $\mathrm{L}_{\alpha}$ phase (incorrectly assigned to a $\mathrm{V}_{2}$ phase in [51,53-55]) is suppressed [67], and a decrease is observed in the temperature of the mesophase-to-liquid transition. The results are consistent with a swelling of the lattice due to incorporation of alkane in the mesophase, and fusion of this on heating. This is similar to the model proposed by Little [26], and in general, similar swelling is likely with all non-coordinating solvents, which at high solvent mole fractions will lead to break-up of the lattice and formation of a liquid phase. The temperature of this transition will depend upon both the degree of penetration of the solvent and specific solute-solute and solvent-solvent interactions. In the liquid phase, repulsion between the head group and organic solvents dictates that the carboxylates will normally be present as aggregates. However, as discussed elsewhere $[16,18,19]$, it is likely that these aggregates will have structures related to those of the mesophases present in the pure compound, i.e. they will have a lamellar structure. The present ${ }^{13} \mathrm{C}$ NMR results are consistent with this, and small angle neutron scattering experiments are planned to obtain more information on these aggregates.

Within this model, the dramatic increase in solubility at a certain temperature may be most easily understood as the transition from the two phase to one phase region in the binary phase diagram lead(II) carboxylate/organic solvent, rather than as a cooperative phenomenon, as observed with aqueous surfactant solutions. Increasing concentration of the carboxylate (decreasing mole fraction of solvent) will increase the solubility temperature and aggregate size, as observed experimentally.

In contrast to the behaviour in solvents such as toluene, in solvents such as alcohols, solvent coordination to the metal ion and interaction with the carboxylate group are also possible and may affect the solubility behaviour, as can be see from the differences in behaviour in pentanol, octanol and glycerol. Support for this comes from studies on the system lead(II) tetradecanoate/octadecanol over the complete composition range [34], where solubility temperatures are higher than those predicted from the ideal freezing equation.

Addition of water to solutions of the lead(II) soaps in organic solvents appears to produce a different structure, possibly due in part to hydration of the lead(II) cation. However, as with incorporation of water into magnesium(II) and calcium(II) surfactant systems in organic solvents [68], it is probable that the number of water molecules which can be incorporated is limited just to the head group region, and that no true, extensive water-in-oil microemulsion phase is formed.

\section{Acknowledgments}

We thank, POCTI, FCT and FEDER for financial support.

\section{References}

[1] J.N. Israelachvili, D.J. Mitchell, B.W. Ninham, J. Chem. Soc. Faraday Trans. 272 (1976) 1525.

[2] J.N. Israelachvili, Intermolecular and Surface Forces, Academic Press, London, 1985.

[3] K. Holmberg, B. Jönsson, H. Kronberg, B. Lindman, Surfactants and Polymers in Aqueous Solution, second ed., Wiley, Chichester, 2003.

[4] D.F. Evans, H. Wennerström, The colloidal domain, in: Where Physics, Chemistry, Biology and Technology Meet, second ed., Wiley-VCH, New York, 1999.

[5] F.J. Buono, M.L. Feldman, third ed. in: H.F. Mark, D.F. Othmer, C.G. Overberger, G.T. Seaborg (Eds.), Kirk-Othmer Encyclopedia of Chemical Technology, vol. 8, Wiley, New York, 1979, p. 34.

[6] R.G. Bossert, J. Chem. Educ. 27 (1950) 10.

[7] G.D. Parfitt, J. Peacock, in: E. Matijević (Ed.), Surface and Colloid Science, vol. 10, Plenum, New York, 1978, p. 163.

[8] M.S. Akanni, E.K. Okoh, H.D. Burrows, H.A. Ellis, Thermochim. Acta 208 (1992) 1.

[9] H. Yamada, M. Tanaka, Adv. Inorg. Chem. Radiochem. 29 (1985) 143.

[10] K. Binnemans, C. Görller-Walrand, Chem. Rev. 102 (2002) 2303.

[11] B. Donnio, Curr. Opin. Colloid Interface Sci. 7 (2002) 371.

[12] A.G. Koenig, J. Am. Chem. Soc. 36 (1914) 951.

[13] A.S.C. Lawrence, Trans. Faraday Soc. 34 (1938) 660.

[14] J.D. Piper, A.G. Fleiger, C.C. Smith, N.A. Kerstein, Ind. Eng. Chem. 31 (1939) 307.

[15] R.D. Vold, M.J. Vold, J. Phys. Colloid Chem. 52 (1948) 1424.

[16] E.P. Martin, R.C. Pink, J. Chem. Soc. (1948) 1750.

[17] S.M. Nelson, R.C. Pink, Nature 169 (1952) 620.

[18] S.M. Nelson, R.C. Pink, J. Chem. Soc. (1952) 1744.

[19] S.M. Nelson, R.C. Pink, J. Chem. Soc. (1954) 4412.

[20] C.R. Singleterry, J. Am. Oil Chem. Soc. 32 (1955) 446.

[21] J.G. Honig, C.R. Singleterry, J. Phys. Chem. 60 (1956) 1108.

[22] N. Pilpel, Trans. Faraday Soc. 56 (1960) 893.

[23] N. Pilpel, Trans. Faraday Soc. 57 (1961) 1426.

[24] I. Satake, R. Matuura, Kol. Z. 176 (1961) 31.

[25] H. Kambe, Bull. Chem. Soc. Jpn. 35 (1962) 265.

[26] R.C. Little, J. Colloid Interface Sci. 21 (1966) 266.

[27] W.U. Malik, A.K. Jain, O.P. Jhamb, J. Chem. Soc. (A) (1971) 1514.

[28] J.A. Wood, C.P. Rycroft, Colloid Polym. Sci. 253 (1975) 311.

[29] J.A. Wood, A.B. Seddon, Colloid Polym. Sci. 263 (1985) 600.

[30] H.D. Burrows, H.A. Ellis, Thermochim. Acta 52 (1982) 121.

[31] M.S. Akanni, H.D. Burrows, H.A. Ellis, D.N. Asongwed, H.B. Babalola, P.O. Ojo, J. Chem. Tech. Biotechnol. 34A (1984) 127.

[32] Z. Zhou, Y. Georgalis, W. Liang, J. Li, R. Xu, B. Chu, J. Colloid Interface Sci. 116 (1987) 473.

[33] Y. Fujii, N. Nakasuka, M. Tanaka, H. Yamada, M. Mizuta, Inorg. Chem. 28 (1989) 3600.

[34] M.S. Akanni, N.A. Abass, Liq. Cryst. 6 (1989) 597.

[35] P. Terech, V. Schaffhauser, P. Maldivi, J.M. Guenet, Langmuir 8 (1992) 2104.

[36] C. Dammer, P. Maldivi, P. Terech, J.-M. Guenet, Langmuir 11 (1995) 1500.

[37] K. Binnemans, P. Martello, I. Couwenberg, H. DeLeebeeck, C. Görller-Walrand, J. Alloys Compd. 303-304 (2000) 387.

[38] K.N. Mehrotra, S.K. Upadhyaya, J. Am. Oil Chem. Soc. 67 (1990) 464.

[39] K.N. Mehrotra, M. Chauhan, R.K. Shukla, J. Am. Oil Chem. Soc. 67 (1990) 446.

[40] K.N. Mehrotra, M.K. Rawat, Bull. Chem. Soc. Jpn. 63 (1990) 3635.

[41] K.N. Mehrotra, M. Chauhan, R.K. Shukla, J. Appl. Polym. Sci. 55 (1995) 431.

[42] K.N. Mehrotra, R.K. Shukla, M. Chauhan, Bull. Chem. Soc. Jpn. 68 (1995) 1825

[43] K.N. Mehrotra, N. Sharma, Monatsh. Chem. 127 (1996) 257.

[44] N. Pilpel, Chem. Rev. 63 (1963) 221. 
[45] J. Lyklema, Adv. Colloid Interface Sci. 2 (1968) 65.

[46] P.A. Winsor, Chem. Rev. 68 (1968) 1.

[47] A.S. Kertes, H. Gutman, in: E. Matijević (Ed.), Surface and Colloid Science, vol. 8, Plenum, New York, 1975, p. 193.

[48] H.D. Burrows, in: D.M. Bloor, E. Wyn-Jones (Eds.), The Structure, Dynamics and Equilibrium Properties of Colloidal Systems, Kluwer, Dordrecht, 1990, p. 415.

[49] B. Smit, P.A.J. Hilbers, K. Esselink, L.A.M. Rupert, N.M. van Os, A.G. Schlijper, Nature 348 (1990) 624.

[50] E. Ruckenstein, R. Nagarajan, J. Phys. Chem. 84 (1980) 1349.

[51] S.O. Adeosun, S.J. Sime, Thermochim. Acta 17 (1976) 351.

[52] S.O. Adeosun, S.J. Sime, Thermochim. Acta 27 (1978) 319.

[53] H.A. Ellis, Mol. Cryst. Liq. Cryst. 139 (1986) 281.

[54] A.M. Amorim da Costa, H.D. Burrows, C.F.G.C. Geraldes, J.J.C. Teixeira Dias, C.G. Bazuin, D. Guillon, A. Skoulios, E. Blackmore, G.J.T. Tiddy, D.L. Turner, Liq. Cryst. 1 (1986) 215.

[55] C.G. Bazuin, D. Guillon, A. Skoulios, A.M. Amorim da Costa, H.D. Burrows, C.F.G.C. Geraldes, J.J.C. Teixeira Dias, E. Blackmore, G.J.T. Tiddy, Liq. Cryst. 3 (1988) 1655.

[56] A. Sanchez Arenas, M.V. Garcia, M.I. Redondo, J.A.R. Cheda, M.V. Roux, C. Turrion, Liq. Cryst. 18 (1995) 431.
[57] E. Alami, M. Almgren, W. Brown, J. François, Macromolecules 29 (1996) 2229.

[58] W. Brown, K. Schillen, M. Almgren, S. Hvidt, P. Bahadur, J. Phys. Chem. 95 (1991) 1850.

[59] J. Jakes, Czech. J. Phys. B38 (1988) 1305.

[60] G. Feio, H.D. Burrows, C.F.G.C. Geraldes, T.J.T. Pinheiro, Liq. Cryst. 9 (1991) 417.

[61] A. Seidel, Solubility of Organic Compounds, third ed., van Nostrand, New York, 1941.

[62] L. Magid, in: W. Brown (Ed.), Dynamic Light Scattering, Clarendon, Oxford, 1993 (Chapter 13).

[63] R.C. Weast (Ed.), CRC Handbook of Chemistry and Physics, 59th ed., CRC Press, West Palm Beach, 1979, p. F57.

[64] G. Feio, H.D. Burrows, C.F.G.C. Geraldes, T.J.T. Pinheiro, J. Chem. Soc. Faraday Trans. 89 (1993) 3117.

[65] H. Saitô, Magn. Reson. Chem. 24 (1986) 835.

[66] M.P. Stevens, Polymer Chemistry, Oxford University Press, New York, 1990 (Chapter 2).

[67] S.O. Adeosun, W.J. Sime, S.J. Sime, Thermochim. Acta 19 (1977) 275.

[68] A. Khan, K. Fontell, B. Lindman, J. Colloid Interface Sci. 101 (1984) 193. 